\title{
Wild Animals in Our Backyard. A Contextual Approach to the Intrinsic Value of Animals
}

\author{
Jac. A. A. Swart · Jozef Keulartz
}

Received: 19 January 2011/ Accepted: 27 January 2011 / Published online: 20 February 2011

(C) The Author(s) 2011. This article is published with open access at Springerlink.com

\begin{abstract}
As a reflection on recent debates on the value of wild animals we examine the question of the intrinsic value of wild animals in both natural and manmade surroundings. We examine the concepts being wild and domesticated. In our approach we consider animals as dependent on their environment, whether it is a human or a natural environment. Stressing this dependence we argue that a distinction can be made between three different interpretations of a wild animal's intrinsic value: a species-specific, a naturalistic, and an individualistic interpretation. According to the species-specific approach, the animal is primarily considered as a member of its species; according to the naturalistic interpretation, the animal is seen as dependent on the natural environment; and according to the individualistic approach, the animal is seen in terms of its relationship to humans. In our opinion, the species-specific interpretation, which is the current dominant view, should be supplemented-but not replaced by-naturalistic and individualistic interpretations, which focus attention on the relationship of the animal to the natural and human environments, respectively. Which of these three interpretations is the most suitable in a given case depends on the circumstances and the opportunity for the animal to grow and develop according to its nature and capabilities.
\end{abstract}

\footnotetext{
Jac. A. A. Swart $(\bowtie)$

Faculty of Mathematics and Natural Sciences, Science and Society Group (SSG),

Energy and Sustainability Research Institute Groningen (ESRIG), University of Groningen, PO Box 221, 9747 AG Groningen, The Netherlands

e-mail: j.a.a.swart@rug.nl

J. Keulartz

Applied Philosophy Group, Wageningen University, Hollandseweg 1, 6706 KN Wageningen, The Netherlands

e-mail: jozef.keulartz@wur.nl

J. Keulartz

Institute for Science, Innovation and Society, Radboud University, Nijmegen, The Netherlands
} 
Keywords Intrinsic value $\cdot$ Wild animals · Domestication ·

Specific and non-specific care $\cdot$ Capabilities

\section{Introduction}

In recent decades we have seen growing attention being paid to the moral position of wild animals, as they are increasingly being affected by human activities. Worldwide, their territories are increasingly fragmented, contaminated, and disturbed by for example, transport activities and facilities, tourism, urban development, and agriculture. Between 1970 and 2007, the populations of almost 30 percent of vertebrate species in the world declined with species in tropical areas appearing to be especially vulnerable (WWF 2010).

However, it is not only socioeconomic developments that affect animal wildlife. The increasing meddling of humans in the natural world is also illustrated by the rise of the discipline of conservation medicine, implying human interventions in wildlife populations to reduce zoonotic threats to both human and animal populations (Meffe 1999; Daszak et al. 2000). Also ecological research and nature conservation efforts have an impact on the welfare of wild animals (Putman 1995; Swart 2004; Minteer and Collins 2008). For example, transponders and transmitters are implanted in the wild animal's body to investigate its physiology and behaviour under natural circumstances (Wilson and McMahon 2006; Casper 2009).

Another development is the re-introduction of wild animals to restore damaged natural areas. Such introductions or reallocations of animals may have negative consequences for their welfare (Minteer and Collins 2008). For example, otters taken from natural areas in Eastern European countries have been introduced into Dutch reserves in order to increase the naturalness or ecological functioning of these areas. However, this may have a negative effect on the welfare of these animals (see e.g. van 't Hof and van Langevelde 2004, 2005; van Liere and van Liere 2005).

Not only wild animals that are being brought into such areas; domesticated animals-especially ungulates - have also been introduced into natural areas, with the intention that they will 'dedomesticate' and return to a natural way of life in succeeding generations. A well known and widely discussed case is the introduction of Heck cattle and Konik horses into the Oostvaardersplassen reserve in the Netherlands since the early 1990s to increase the naturalness of these areas. Winter is a difficult period for these animals because of the limited availability of food and the weather conditions. Several times it has led to starvation among these animals and subsequently to political and public unrest (ICMO 2006; ICMO2 2010). Supporters of this de-domestication management claim that intervention to prevent starvation will ultimately undermine the self-sufficiency of the population and will inhibit its adaption to the existing circumstances. They argue that high mass starvations also incidentally happen in other natural reserves, for example the Serengeti reserve in Africa (Vera 2009). However, critics argue that humans have bred these animals and introduced them into the reserve. Moreover, their natural habitat has been limited by fencing and natural forces as e.g. predation do not affect 
their populations. From this standpoint, they should primarily be considered as kept animals that fall under human responsibility (RDA 2005).

Discussions about the moral position of wild, semi-wild animals, or captured wild animals not only involve welfare considerations. When an wild animal's welfare is not at stake the increased human interference with them may nevertheless be morally questioned, as the moral standing of wild animals is also determined by wildness itself. For example, in several countries there has been a heated public debate on the fate of wild animals in circus. NGOs in several countries have protested against the use of these animals in circus, not only for presumed welfare reasons, but also because they consider this as an infringement on the dignity and intrinsic value of being wild (see also Kiley-Worthington 1990; Radford 2007; Hopster et al. 2009; Keulartz and Swart 2009).

The Dutch Flora and Fauna Act also recognize the moral state of being wild. It explicitly mentions the intrinsic value of wild animals. Based on this Act the governmental guidelines regarding the hospitalization of seals state that people should respect the inherent individuality of animals living in the wild. This means that interventions involving the intrinsic value of the animal can only be permitted in extraordinary circumstances. Hospitalization of animals that are ill, wounded, or otherwise in need is an intervention affecting their intrinsic value. After all, the inherent individuality of an ill, wounded or dying animal living in the wild must also be respected'. (LNV 2003: p. 7, our translation).

Thus, according to the latter line of reasoning, the intrinsic value of wild animals implies non-intervention even if this leads to the reduced welfare of the animals concerned, whereas the recognition of intrinsic value of animals falling under our direct responsibility, as is the case for kept and domesticated animals, implies taking care of their welfare. The apparent contradiction between the principle of nonintervention for wild animals and the principle of taking care of the animal that falls under our responsibility was usually resolved by excluding wild animals from our circle of responsibility. For example, Verhoog (1999) states, [b]y making an animals survival and well-being dependent on human action, man has become responsible for it, whereas such responsibility does not exist with respect to wild animals (Verhoog 1999 , p. 274). Similarly, Norton (1995, p. 105) argues that [b]y deciding to respect their wildness, we have agreed not to interfere in their daily lives or deaths.

However, this way of reasoning seems to fail to take account of the increasing interference of humans with wild animals as described above. Both the principle of non-intervention and that of taking care of their welfare seem both to be applied. The concept of the intrinsic value of wild animals and what is meant by wildness or domestication therefore needs to be elucidated. In this article we aim to analyse both issues. We will begin by examining the concepts of wild and domesticated animals and argue for recognizing several classes of dependence of animals on their environment. On this basis, we explore the meaning of the term 'intrinsic value' in more detail. We argue that a distinction can be made between three different interpretations of a wild animal's intrinsic value: a species-specific, a naturalistic, and an individualistic interpretation. In our opinion, which of these three interpretations is the most suitable in a given case depends on the opportunity for the animal to grow and develop according to its nature and capabilities and also on practical circumstances. 


\section{Domestication, Wildness and Dependence}

According to Dutch law, a wild species is a species that is naturally found in the wild (Staatsblad [Bulletin of Acts and Decrees] 2002). ${ }^{1}$ Due to the increasing human interference with wild animals in and outside the human sphere and dedomestication experiments this definition is not clear-cut. The concepts of domestication and wildness should therefore be more clearly defined. To begin with, we can distinguish between a biological approach and a 'sociological' approach to domestication. According to the biological definition, domestication must be considered as a process by which animals adapt to humans and the environment they provide. As a consequence, the phenotype of the animal will change compared to their wild counterparts. Subsequently, genetic changes may occur over generations (Price 1999). Some species appear easier to domesticate than others because their genetically determined characteristics naturally conform better to human systems. This is sometimes called 'pre-adaptation' and it applies in particular to herd animals and social animals with behaviour patterns based on a hierarchy of dominance. When keeping or domesticating these animals, humans take on the role of leader of the herd or group (Smith 1998; Kiley-Worthington 1990; Palmer 1995).

The sociological approach to domestication primarily considers domestication as a process by means of which animals function in or form a part of human social systems and/or practices. In other words, domestication brings animals under human dominion, making them dependent on human society with respect to their social organization, territory, reproduction and food supply (Clutton-Brock 1989; Hettinger and Throop 1999). From this perspective, keeping wild animals in a zoo is a form of domestication, even if it is possible to allow the animal to maintain its original biological characteristics and behaviour. The same can be said, for example, about systematically giving supplementary food to wild animals, as sometimes happens for hunting purposes. Changes in biological characteristics as a result of domestication are according to this sociological view secondary changes, an adaptation to the human environment in which the animal lives (Clutton-Brock 1981, p. 21).

The sociological definition of domestication has a wider scope, as it also includes captive wild animals and feral animals that are more or less dependent on human settlements for their subsistence. However, both approaches share the aspect of dependence. Wild animals are free from human interference and only dependent on a well-functioning relationship with their natural environment, whereas domesticated animals and animals under human dominion are dependent on humans for their subsistence. Thus, in general, domestication implies a shift towards human dependence and de-domestication a shift towards natural dependence.

We have used these two perspectives on domestication to hypothesize a number of classes of dependence of an animal on its environment. Firstly, we distinguished three levels of human dominion over animals: animals that live in the wild and are not or barely dependent on humans; animals that have a medium level of

\footnotetext{
${ }^{1}$ With the exception of cats, dogs and a list of other species which are allowed to be kept for specific purposes of production.
} 
Table 1 Six hypothetical classes of on the dependence continuum

\begin{tabular}{|c|c|c|c|}
\hline Class & Dependence & Adaptability & Examples \\
\hline I & Low & Low & $\begin{array}{l}\text { Wild animals that live in their natural habitat and that do not easily } \\
\text { domesticate or adapt to human environs }\end{array}$ \\
\hline II & Low & High & $\begin{array}{l}\text { Wild animals that will domesticate or adapt to the human environs } \\
\text { rather easy }\end{array}$ \\
\hline III & Medium & Low & $\begin{array}{l}\text { Animals that seek out human environs as a result of the decline of } \\
\text { their habitat, such as the polar bear }\end{array}$ \\
\hline IV & Medium & High & Feral animals and synanthropes (house mice, sparrows) \\
\hline $\mathrm{V}$ & High & Low & Wild animals from category I that live in zoos or circuses \\
\hline VI & High & High & $\begin{array}{l}\text { Pet animals, livestock, wild animals from category II that live in } \\
\text { human environs as zoos and circuses }\end{array}$ \\
\hline
\end{tabular}

dependency on humans, for example, non-captive animals that depend on humans and therefore live close to human settlements; and animals that live under human dominion, being highly dependent on human care. Secondly, we distinguished between animals that adapt easily or are already well adapted to human environs (and thus domesticated from a biological point of view) and animals that are not adapted or hardly to adapt (and thus still wild according to the biological definition). The combination of these two dimensions produces six hypothetical classes of human dependence, as shown in Table 1.

\section{The Species-Specific Interpretation of Intrinsic Value}

Animals are increasingly recognized as having intrinsic value, that is, there is a recognition that animals that fall under our responsibility are also part of our moral circle, and whether these animals flourish is also our concern. In general, this concept implies that the animal's nature and capabilities must be respected and that its interests must be taken into account. ${ }^{2}$ However, the growing moral attention paid to animals has been often focused only on kept or domesticated animals (Waelbers et al. 2004), thus animals we have considered as class V or VI in Table 1. But even this attention is rather from a rather recent date (Singer 1990; Regan 1983). Arthur Schopenhauer claimed that there was a sign hanging before the door to Western ethics reading, 'Tiere müssen draußen bleiben' ('Animals must remain outside'), and for a long time this was the case. This way of thinking was inspired by the influential ethics of Immanuel Kant who stressed the idea of a rational and autonomous human being. Animals had no place in such a system. Although this opinion was widely shared, it did not mean that all behaviours towards animals were permissible or acceptable. Rather, the moral place of animals was derived from their supposed effects on the interrelationship between humans. The thought was that

\footnotetext{
${ }^{2}$ Some authors use a different term for what we here call intrinsic value, such as inherent value or inherent worth. In general we will refer to intrinsic value in this artile, but will indicate the terms as used by other authors.
} 
animal abuse would lead to moral corruption, for 'who is cruel to animals becomes hard also in his dealings with men' (Kant 1997, p. 240).

Many modern philosophers are also unclear about the moral position of animals. For example, John Rawls recognizes that animals are part of our moral circle, but he excludes them from his own theory of justice, which, like Kant's approach, is based on the idea that some kind of rationality is necessary in order to fall under a moral code (Rawls 1971, p. 512). However, utilitarian philosophers as e.g. Singer (1990) avoid the issue of rationality and consider animals to be within our moral circle because they possess the morally relevant ability to suffer. 'The question is not, Can they reason? nor Can they talk? but Can they suffer?', according to the famous and often cites statement by Bentham (1823). According to Peter Singer, an intrinsic value is something that is good or desirable in itself (Singer 1993, p. 274). Thus, avoiding suffering may be considered as an intrinsic value (as it is for humans) but this does not imply the intrinsic value of animals themselves.

Regan (1983), building on Kant's concepts, does however offer a theoretical foundation for the intrinsic value of animals themselves. The basis for attributing intrinsic value to human beings, according to Regan, is found in their status as autonomous subjects. Regan introduces the term 'subject-of-a-life', which is broader than the definition of a person on which Kant based his ethics. According to Regan, animals are, like humans, subjects-of-a-life. They have subjective experiences, can experience the quality of their lives, and enter into and maintain relationships with others. Regan claims that, just like a human being, an animal has an 'inherent value', implying that an animal also has moral rights. Thus, an intrinsic value is ascribed to an individual animal on the basis of it being a subject-of-a-life, meaning that it may be considered morally questionable for humans to utilize animals even when there is no suffering involved. If wild animals are seen as subjects-of-a-life, the implication is that we should leave them alone. 'Let them be', as Regan says (1983, p. 361). This entails refraining from domesticating wild animals or bringing them into a human environment. For Regan, however, the respect for an animal's wild state derives from its status as a subject. In his view, animals to which the concept of subject does not apply cannot be ascribed intrinsic value. On this basis, he restricts intrinsic value to mammals that are at least 1 year old. An animal's wild state-which of course does not depend on species or age-is not by itself a sufficient reason to ascribe intrinsic value to that animal.

Regan's approach was criticized as anthropocentric because it takes the human consciousness paradigm as a starting point (Verhoog 1999). As an alternative, the biocentric approach, which was put forward by Paul Taylor (1986), assumes a different premise on the basis of which to attribute intrinsic value to animals. Taylor states that all organisms have 'inherent worth' because, as 'teleological centres of life', they have a good of their own. This good consists of fulfilling their capabilities and satisfying their needs in a manner suited to their species. Therefore, they deserve moral consideration without exception.

In answer to the question of why having an individual good is morally relevant, the Dutch bio-ethicists Bart Rutgers and Robert Heeger state that a situation in which the good of animals is realized is better than a situation in which that good is not or only partially realized (Rutgers and Heeger 1999). According to these 
authors, '[t]he term "inherent worth" expresses a substantial claim: the animal's intactness and its species-specific capacities and functions constitute a value towards which an attitude of moral respect is appropriate' (Rutgers and Heeger 1999 , p. 44). Such respect for animals is expressed, in particular, through respect for an animal's integrity, which is defined as 'the wholeness and completeness of the animal and the species-specific balance of the creature, as well as the animal's capacity to maintain itself independently in an environment suitable to the species' (Rutgers and Heeger 1999, p. 45).

What does this mean for the wild animal? Just as in Regan's view, we can posit that a wild animal in its natural environment is probably best served by remaining in that environment. However, it does not automatically follow that wild animals kept in captivity should be placed in a natural environment. The good of wild animals kept in human surroundings may in theory also be served by keeping them in those surroundings. What the good of the creature might be and what the human role is in determining that good remains unclear. For example, the question can be raised whether the introduction of wild or semi-wild animals into nature reserves and their being left to their fate serves the good of those animals, as living a natural life may also lead to suffering due to bad living conditions (Klaver et al. 2002; Swart 2007).

Both the subject approach and the biocentric approach consider the individual animal in terms its species characteristics (or higher biosystematic concepts). Thus, according to Regan's approach, an animal is considered a subject-of-a-life because of the neuronal capabilities of mammals (older than 1 year), whereas the biocentric approach holds that animals must satisfy their species-specific needs, for example a pig must be able to root, a rodents must be able to gnaw, and dog must be able to form social bonds within a pack, whether with humans or other dogs. Because of this focus on species-specific characteristics and needs we may label these approaches species-specific interpretations of the intrinsic value of animals.

\section{The Naturalistic Interpretation of Intrinsic Value}

The species-specific approach, described above ignores however the strong dependence of wild or freely moving animals (animals we have put in classes I to IV of Table 1) on their natural or semi natural environment. An alternative is the contextual approach, in which the animal is considered strongly in relation to its environment (Swart 2005, 2007). Animal ecology and animal behavioural sciences show that wild animals have a complex relationship with their environment. Animals are constantly exchanging information and material with their natural environment and are greatly dependent on it. The quality of the environment is essential to the question of whether the animal can subsist. However, we must be careful not to form a romantic idea of this natural state. Animals that live in the wild, free from human interference, can suffer greatly from diseases and harsh circumstances. Nevertheless, for wild animals in general, it is not their individual well-being which indicates the degree to which they can flourish, but the degree to which they are able to lead a natural life in terms of foraging for food, reproducing, avoiding enemies, etc. (Swart 2004). 
Unfortunately, as already mentioned in the introduction, this natural condition is increasingly becoming an exception. Wild animals increasingly find themselves adrift in this landscape, not only as a result of the reduction and fragmentation of their natural habitat, but also due to climate change and increased transport and tourism. At the same time, built-up areas and infrastructure increasingly limit the animal's freedom of movement. Nature reserves are mere islands in an everadvancing landscape of human civilization.

Assuming that the intrinsic value of wild animals indeed implies non-intervention in their lives and that they are able to flourish in their natural, non-disturbed habitat, we must take measures to protect that habitat and restore it where necessary and possible. The responsibility for carrying out such measures can be seen as considered as the 'naturalistic interpretation' of the wild animal's intrinsic value. The naturalistic interpretation is related but not identical to the ecocentric or holistic approach to intrinsic value (Callicott 1989). The ecocentric approach is also contextual in nature as it stresses the animal's role in the ecosystem of which the animal is a part; however, the value placed on the animal is instrumental and derived from the intrinsic value of the ecosystem. In contrast, the naturalistic approach is based on the idea that the animal should be viewed in terms of its dependence on nature and thus not in terms of its instrumental relationship to the natural environment.

\section{Specific and Non-Specific Care}

Swart (2005) introduced the term 'non-specific care', for care focused on maintaining and developing the natural environment of the wild animal so that it can lead a natural life. As the counterpart of non-specific care, Swart (2005) suggests 'specific care' for animals kept by humans, including domesticated animals. These animals are entrusted to our care or are placed in human environments, and are therefore dependent on us for their welfare and needs. So we may conclude that the naturalistic interpretation of intrinsic value implies nonspecific care for wild animals, whereas the species-specific interpretation leads to specific care for kept and or domesticated animals.

The care model of Swart (2005) applies the concept of a continuum between 'wild' and 'domesticated' that was put forward by Klaver et al. (2002). Accordingly, specific and non-specific care also relates to the level of wildness or domestication by degrees, respectively. Although both types of care exclude each other to a certain extent, they do not rule each other out completely since there may be good reason to provide specific care when an animal happens to find itself in distress. In comparison, non-specific care of domesticated animals is required by legislation to prevent their exaggerated exploitation (Swart 2005, p. 259). For instance, the Dutch Animal Health and Well-being Act (Gezondheids-en welzijnswet voor dieren) lists both species-specific and general requirements pertaining to shelter, hygiene and veterinary care for animals.

The practical applicability of the care model was recently illustrated by a report of the Second International Commission on Management of the Oostvaardersplassen 
concerning the management of the introduced animals in this nature reserve. The Dutch government had established this committee because of public concern as described in the introduction of this paper. The commission refers to the care model and concludes that the introduced herbivores (especially Heck cattle and Konik horses) must be considered as 'in between fully wild and domesticated/managed' and that 'both specific care (...) and nonspecific (...) cares has to take place to reflect the moral and ethical considerations for these animals' (ICMO2 2010: 46). See also: Keulartz et al. 1998a, b; Klaver et al. 2002; Vorstenbosch et al. 2001; Waelbers et al. 2004; Swart 2005, 2007; Keulartz 2009; and Gamborg et al. 2010 for reviews and discussions on the case of introduced animals in the Oostvaardersplassen.

Based on the concept of domestication and dependence of animals on their environment, discussed above, we have adapted the care model by using the animal's dependence as the $\mathrm{X}$ axis, rather than the wild-domesticated continuum used in the first version (Swart 2005). Accordingly, we have hypothetically located the various classes of dependence from Table 1 in the model (see Fig. 1).

\section{The Capabilities Approach and Individualistic Interpretation of Intrinsic Value}

The species-specific approach of intrinsic value emphasizes specific care for domesticate animals. In addition, also wild and semi-wild animals living in nonnatural conditions, such as zoo and circus animals, need-as long as they are in the human environment-specific care geared to the animal's species-specific characteristics and the particular human environment in which it lives. Such animals are more or less dependent on humans to realize their own good in accordance with their species-specific capabilities. This attention to an animal's capabilities is also

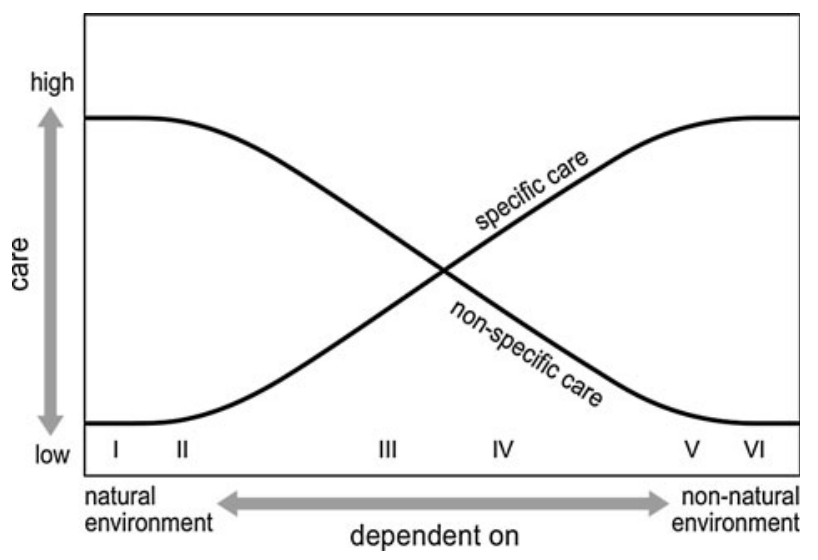

Fig. 1 Non-specific and specific care on the continuum ranging from natural to non-natural habitats for animals. The Roman numerals refer to the classes of dependence or human dominion, given in Table 1. Adapted from Swart (2005) 
found in the philosophy of Martha Nussbaum (2006). She derives her 'capabilities approach' from the work of the economist and Nobel Prize winner Amartya Sen, who uses the concept of human capabilities in order to study questions of justice and development in society. The core of Sen's approach is that a just division of goods in a society will give the members of that society the opportunity to realize their essential or basic capabilities (Sen 1979). Nussbaum applies this idea to the question of justice for animals. In her view, individual animals of all species deserve a fair chance to flourish; in other words, to be able to fully develop the capabilities and capacities which are specific both to their species and to their individual characters. According to Nussbaum, to be a living entity, to have a healthy life, to experience pleasure, pain or emotion, or the power to behave in a certain way or to play, all such capacities imply that animals possess a moral worth. Humans have the moral responsibility towards animals that fall under their dominion to ensure that they can actually realize these capabilities.

Nussbaum attaches great importance to the possibility for animals to enjoy a certain measure of sovereignty and to live an autonomous life. As many others she admits that the habitat of wild animals is in increasingly restricted by human activities, meaning that these animals are less able to flourish. Therefore, Nussbaum argues in favour of what we earlier called non-specific care: care for the living environment (habitat) of animals. In addition, she points out that many species have evolved in a long-lasting symbiotic process with humans, resulting in mutual dependence. In these cases, the concept of specific care also applies.

It is clear, then, that the lives of many animals are variously intertwined with human activities and with the care of animals in a specific or non-specific sense. We cannot casually abandon wild animals to their fate. Nor can we, as many romantics would wish, release kept animals into the wild without any form of human intervention. However, it is indefensible not to allow animals under human dominion to develop their natural capabilities. Nussbaum makes the case for a form of paternalism which is sensitive to the individual nature of the animals entrusted to our care. This would be a kind of care that allows animals to flourish. Zoos and wildlife parks can play a part in this because, unfortunately, an increasing number of animal species are better off in these places than in the wild, simply because their habitats are seriously threatened.

The capabilities approach can do justice to the dynamic character of the interaction between species-specific behaviour and the environment. The intrinsic value of animals implies that the care of animals for which humans are responsible, should not be measured against the ideal of a wild environment but rather by the possibilities that a given environment offers to animals to realize their natural capabilities. Apes, for instance, require the possibility of explorative behaviour, but that need can be met in a variety of ways - by searching for food, for example, but also by playing computer games. In the same way, tigers must be able to express their predation behaviour. In a natural environment this would occur by hunting prey, while in a zoo this could be achieved by providing a ball on a rope which the animal can 'hunt'.

The capabilities approach suggests, along with care geared towards speciesspecific needs, attention to the needs and capabilities of the individual animal. In 
addition, in Nussbaum's view, care for kept animals does not exclude the idea that animals may be made to do the things which humans require of them. As part of her paternalistic approach, Nussbaum states that domesticated and/or kept animals, like children, can benefit from training and discipline, as long as their species-specific and individual capabilities are taken into account.

This last point is of particular importance in the case of animals connected to humans in a task-related capacity, such as dressage horses, guide dogs, or circus animals. If they are to succeed, the emphasis must be on individual care, a form of specific care that not only focuses on species-specific characteristics, but also and especially on the individual nature of the particular animal. Animals that carry out these sorts of specific tasks usually have a particularly close relationship with humans based on mutual trust (Haraway 2006, 2008). Rather than Jeremy Bentham's famous question 'Can animals suffer?' Donna Haraway prefers to ask the question, 'Can animals play? Or work?' In her opinion, training animals is not equivalent to subduing or oppressing them. Haraway bases her ideas in part on the work of the trainer and philosopher Hearne (2007), who emphasizes the reciprocity of working relationships between humans and animals, and the fact that they can both find satisfaction in successfully developing and practising their own capabilities and talents.

Responsibility towards animals in working relationships, according to Haraway, can be seen as 'response ability': the ability to listen to animals and to respond to their needs and desires. This reciprocal relationship also implies the animal's cooperation. Whether a particular situation is morally permissible or reprehensible depends in part on the degree to which animals can 'protest' in cases where their individual wants are not met and where they are forced into docility.

The view that the animal should be able to work, in so doing, can develop its capabilities, is supported by recent insights gained through research into stress in animals. The classic view, the so-called 'homeostatic model', assumes that the animal's well-being is guaranteed if challenges and stress factors in the environment are at a minimum. According to the 'allostatic model', however, an animal possesses physiological and behavioural characteristics that enable it to deal with and adapt to a range of stresses and challenges. Training and stressful experiences can maintain this range and possibly even extend it. However, both too few and too many challenges decrease this range and create reduced resistance, leading to such issues as stereotypical behaviour, panic behaviour and the related problems of wellbeing (Korte et al. 2007).

We regard the capabilities approach as a refinement and concretizing of the biocentric idea of an animal's 'own good'. In particular, the focus on animals' individual characters and capabilities, which, just as in humans, can differ noticeably among animals of the same species, avoids the more species-specific perspective of the biocentric approach. This leads to what could be called individual care for animals. We can therefore refer to an individualistic interpretation along with the naturalistic and species-specific interpretations of intrinsic value. This places animals' flourishing in a broader perspective. 


\section{A Contextual and Pluralistic Approach to Intrinsic Value}

Thus far, various interpretations of the intrinsic value of the animal have been distinguished and placed in context. In our pluralistic approach, the environment, in which the animal lives or matures, and its capability to flourish in that environment determine which interpretation is most suitable and which type of care the animal requires. This contextual approach regards 'the animal in its environment' as the analytical unit. This can vary from a natural to a human environment (see also Table 1), in which a distinction can be drawn between a naturalistic, a speciesspecific, and an individualistic interpretation of intrinsic value.

According to our approach, the animal must be able to anticipate and respond to the demands of its environment and to learn from its experiences. This is reasonably obvious in nature. However, it applies to human environments where the animal can undergo learning experiences and challenges as substitutes for natural learning experiences and challenges. In our opinion, the species-specific interpretation, which views the animal as rather separate from its environment, must be supplemented —and not replaced—by naturalistic and individualistic interpretations which focus attention on the dependence of animal on their natural or human environment and their capacity to live in the natural or human environment.

The naturalistic interpretation of intrinsic value implies a negative obligation to guard the animal against human interference and a positive obligation to protect or improve the wild animal's environment (see also Wenz 1988). Animals located in classes I and II in Table 1 should therefore only be brought under specific human care for urgent reasons. Regan's 'let them be' is the starting point in this view. ${ }^{3}$

Urgent reasons for specific care can arise particularly in the case of animals that live freely in proximity to humans but nevertheless show very little adaptation to humans (which we have classified as Class III in Table 1). Often these animals seek out human environs because of a reduction in their natural habitat. The naturalistic interpretation of the intrinsic value of these animals urges us to improve their original living conditions.

The situation may be different for synanthropes, that is, animals which live freely in proximity to humans and which are also adapted to human environs (Class IV, Table 1). Specific to these animals is the fact that they themselves seek out human environs. From the point of view of the species-specific interpretation of intrinsic value, it follows that we must consider the possibilities and limitations of these animals' capability to adapt to the human environment.

Animals that are insufficiently adapted to human environs but nevertheless kept by humans for example in circuses belong to class $\mathrm{V}$ in Table 1. Their moderate or minimal adaptation to human conditions would indicate that there is a large chance that humans fail in allowing them to flourish. Suitable living environments, which will sufficiently meet their species-specific and individual needs, should be sought

\footnotetext{
${ }^{3}$ According to a letter from the Dutch Minister of Agriculture, Nature and Food Quality (LNV), the CITES regulations forbid removing a number of animal species, such as tigers and elephants, from the wild, but this is still possible for other species (Verburg 2009).
} 
for these animals. This may be a zoo, a wildlife park, or possibly the wild, depending on the animal's species-specific and individual characteristics.

The intrinsic value of animals kept by humans and well adapted to human conditions (Class VI in Table 1) seems at first sight not to be a principal issue. This includes house pets, animals used for production, certain domesticated circus animals and animals used in sport, such as dressage horses or dogs which perform obedience trials. These animals can flourish under these circumstances as long as they receive adequate, species-specific and individual care. In general, nature can serve as a source of inspiration for designing environments that will enable the animals to flourish.

However, this group may also include species that are considered wild because the species naturally occurs in the wild (see Staatsblad [Bulletin of Acts and Decrees] 2002). In most cases, this concerns animals whose ancestors were wild but which have been kept by humans, sometimes for generations. This includes e.g. some circus animals and some zoo animals such as camels and elephants. However, the mere fact that animals of the same species live in the wild is not a sufficient reason to place these animals in a more natural environment, as it does not take into account the interests of the individual animal. Nevertheless, in cases where it is proven that these animals are capable of living under more natural conditions, from the point of view of respect for the 'potential wildness' of the animal (Keulartz et al. 1998b) — which can be seen as a capability_reintroduction of the animals should be considered, providing that their well-being will not be substantially harmed and the environment is indeed available for such a return. In many cases such conditions are not fulfilled for such a return and we should provide them with proper type of care and the opportunity to flourish under less natural conditions. What that opportunity entails and to what extent it is called for depends on the species-specific and individual characteristics and capabilities of the animals.

Swart (2005, p. 260) argues that the model of specific and non-specific care is neutral with respect to the act of domestication, or de-domestication as it only describes the required types of care as a function of the level of wildness or domestication. However, if we recognize the naturalistic or species-specific and individualistic interpretations of intrinsic value of animals we may ask whether domestication and de-domestication, thus moving an animal along the axis of wild and domesticated, is really neutral. Taming or keeping a wild animal is not in accordance with its naturalistic intrinsic value, whereas introducing a domesticated animal into the wild may offend its species-specific or individualistic intrinsic value. However, as discussed above, re-introduction or de-domestication of captured wild or semi-wild animals may be desirable sometimes. In addition, externally legitimated reasons, for example eco-ethical considerations may overrule considerations based on the recognition of the animal's intrinsic value we have worked out here.

Moving an animal along the axis of dependence in Fig. 1 should be done very carefully as it may have negative welfare consequences or offend the animal's intrinsic value. However, the allostatic model of well-being described above, implies the existence of a range of conditions under which an animal can flourish. This can be utilized when deciding on the acceptability of (re)introduction 
experiments. Not only does this range enable a change in living conditions, is also possible to train individual animals and extend their resistance within these new living conditions. However, it must be clear that an evolutionary and therefore genetic adaptation to another, more natural environment occurs at the level of populations and often takes generations to complete in cases of domesticated animals. An animal, which is seen as wild and which is under human care does not necessarily need to be placed in a more natural situation-this may even be undesirable. Decisions on these issues should be guided by the practical circumstances and knowledge about the animal and its environment.

Acknowledgments This article was prepared as follow-up to a research project on the intrinsic value of circus animals that was funded by the Dutch Ministry of Agriculture, Nature and Food Quality (LNV), The Hague. We thank the editors of the special issue of Acta Biotheoretica and the three anonymous reviewers for their valuable suggestions, which significantly contributed to our thinking on the complex issue of the intrinsic value of animals.

Open Access This article is distributed under the terms of the Creative Commons Attribution Noncommercial License which permits any noncommercial use, distribution, and reproduction in any medium, provided the original author(s) and source are credited.

\section{References}

Bentham J (1823) Introduction to the principles of morals and legislation, 2nd edn, chapter 17, footnote. http://www.econlib.org/library/Bentham/bnthPML18.html. Accessed 18 Dec 2010

Callicott JB (1989) In defense of the land ethic. State University of New York Press, Albany

Casper RM (2009) Guidelines for the instrumentation of wild birds and mammals. Anim Behav 78:1477-1483

Clutton-Brock J (1981) Domesticated animals from early times. Heinemann \& British Musuem (Natural History), London

Clutton-Brock J (1989) Introduction to domestication. In: Clutton-Brock J (ed) The walking larder. Patterns of domestication, pastoralism, and predation. Unwin Hyman, London, pp 7-9

Daszak P, Cunningham AA, Hyatt AD (2000) Emerging infectious diseases of wildlife-threats to biodiversity and human health. Science 287(5452):443

Gamborg C, Gremmen BM, Christiansen SB, Sandøe P (2010) De-Domestication: ethics at the intersection of landscape restoration and anima welfare. Environ Values 19:57-78

Haraway D (2006) Encounters with companion species: entangling dogs, baboons, philosophers, and biologists. Configurations 14:97-114

Haraway D (2008) When species meet. University of Minnesota Press, Minneapolis

Hearne V (2007) Animal happiness. A moving exploration of animals and their emotion. Skyhorse Publishing, New York

Hettinger N, Throop B (1999) Refocussing ecocentrism: de-emphasizing stability and defending wildness. Environ Ethics 21:3-21

Hopster H, van Dierendonck M, van den Brandt H, van Reenen K (2009) Welzijn van dieren in reizende circussen in Nederland [Welfare of animals in travelling circuses in The Netherlands]. Animal Science Group, Report 212. Wageningen University and Research Centre, Wageningen

ICMO (2006) Reconciling nature and human interests. Report of the International Committee on the Management of large herbivores in the Oostvaardersplassen (ICMO). Wageningen UR WING report 018, The Hague

ICMO2 (2010) Natural processes, animal welfare, moral aspects and management of the Oostvaardersplassen. Report of the 2nd international commission on management of the Oostvaardersplassen (ICMO2). Wing rapport 039, The Hague 
Kant I (1997) Lectures on ethics (trans: Heath P, Schneewind JB (eds)). Cambridge University Press, Cambridge

Keulartz J (2009) Boundary work in ecological restoration. Environ Phil 6(1):35-55

Keulartz J, Swart JAA (2009) De intrinsieke waarde van dieren in performance praktijken. Animal Sciences Group, Wageningen University/University of Groningen. Rapport 216

Keulartz J, van den Belt H, Gremmen B, Klaver I (1998a) Op eigen poten. Ethiek rondom grote grazers. K\&M Tijdschrift voor empirische filosofie 22(3):257-289

Keulartz J, van den Belt H, Gremmen B, Klaver I, Korthals M (1998b) Goede tijden, slechte tijden. Ethiek rondom grote grazers. NWO Ethiek en Beleid, The Hague

Kiley-Worthington M (1990) Animals in circuses and zoos. Chiron's world? Little Eco-Farms Publishing, Harlow. http://the-shg.org/Kiley_Worthington/index.htm. Accessed 30 Dec 2010

Klaver I, Keulartz J, van den Belt H, Gremmen B (2002) Born to be wild. A pluralistic ethics concerning introduced large herbivores in the Netherlands. Environ Ethics 24(1):3-23

Korte SM, Olivier B, Koolhaas JM (2007) A new animal welfare concept based on allostasis. Physiol Behav 92:422-428

LNV (2003) Leidraad opvang gewone en grijze zeehond. Ministry of Agriculture, Nature and Food Quality, The Hague

Meffe GK (1999) Conservation medicine. Conserv Biol 13(5):953-954

Minteer BA, Collins JP (2008) From environmental to ecological ethics: toward a practical ethics for ecologists and conservationists. Sci Eng Ethics 14:483-501

Norton BG (1995) Caring for nature. A broader look at animal stewardship. In: Norton BG, Hutchins M, Stevens EF, Mapple TL (eds) Ethics on the ark. zoos, animal welfare, and wildlife conservation. Smithsonian Institution Press, Washington, pp 102-121

Nussbaum MC (2006) Frontiers of justice. Disability, nationality, species membership. Harvard University Press, Cambridge

Palmer C (1995) Animal liberation, environmental ethics and domestication. Research Paper, no. 1. Oxford Centre for the Environment, Ethics \& Society (OCEES), Oxford

Price EO (1999) Behavioral development in animals undergoing domestication. Appl Anim Behav Sci $65: 245-271$

Putman RJ (1995) Ethical considerations and animal welfare in ecological field studies. Biodivers Conserv 4(8):903-915

Radford M (2007) Wild animals in travelling circuses. The report of the chairman of the circus working group. Department for the Environment Food and Rural Affairs (DEFRA), UK. http://www.defra.gov.uk/foodfarm/farmanimal/welfare/act/secondary-legis/circus.htm. Accessed 30 Dec 2010

Rawls J (1971) A theory of justice. Harvard University Press, Cambridge

RDA (2005) Advies over de wintersterfte 2004-2005 van grote grazers in de Oostvaardersplassen. RDA 05/8. Raad voor Dieraangelegenheden, The Hague

Regan T (1983) The case for animal rights. University of California Press, Berkely, Los Angeles

Rutgers B, Heeger R (1999) Inherent worth and respect for animal integrity. In: Dol M, Fentener van Vlissingen M, Kasanmoentalib S, Visser T, Zwart H (eds) Recognizing the intrinsic value of nature. Van Gorcum, Assen, pp 41-53

Sen A (1979) Equality of what? The Tanner lecture on human values, Delivered at Stanford University May 22, 1979. http://www.tannerlectures.utah.edu/lectures/documents/sen86.pdf. Accessed 30 Dec 2010

Singer P (1990) Animal liberation, New Revised edn. Avon Books, New York

Singer P (1993) Practical ethics, 2nd edn. Cambridge University Press, Cambridge

Smith BD (1998) The emergence of agriculture. Scientific American Library, New York

Staatsblad (Bulletin of Acts and Decrees) (2002) Besluit van 19 April 2002, houdende eisen aan het houden, huisvesten, verzorgen en tonen van wilde dieren in dierentuinen (Dierentuinenbesluit), Staatsblad, 214

Swart JAA (2004) The wild animal as a research animal. J Agric Environ Ethics 17(2):181-197

Swart JAA (2005) Care for the wild. Dealing with a pluralistic practice. Environ Values 14(2):251-263

Swart JAA (2007) Dieren in context. Over de waarde van dieren. Nederlandse Vereniging voor Bioethiek (Dutch Association for Bioethics), Amsterdam

Taylor PW (1986) Respect for nature. A theory of environmental ethics. Princeton University Press, Princeton 
van 't Hof P, van Langevelde F (2004) Reintroduction of the otter (Lutra lutra) in the Netherlands meets international guidelines. Lutra 47(2):127-132

van 't Hof P, van Langevelde F (2005) Reintroduction of the otter in the Netherlands: implementation of international guidelines in the pre-release phase. Lutra 48(2):135-137

van Liere B, van Liere LE (2005) Reintroduction of the otter (Lutra lutra) in the Netherlands: did it really meet international guidelines? Lutra 48(2):131-134

Vera FWM (2009) Land-scale nature development-the Oostvaardersplassen. Br Wildl 20(5):28-36

Verburg G (2009) Letter to the chair of the house of representatives of the states general. 27 July 2009: reference: TRCDL/2009/1439. http://www.rijksoverheid.nl. Accessed 30 Dec 2010

Verhoog H (1999) Bio-ethics and the intrinsic value of animals. Recognizing the intrinsic value of animals. Beyond animal welfare. In: Dol M, Fentener van Vlissingen M, Kasanmoentalib S, Visser T, Zwart H (eds) pp 81-93

Vorstenbosch J, Stafleu F, Bovenkerk B, Tramper R (2001) Doen of laten? Empirische en normatieve vragen rond de opvang van dieren uit het wild. Centrum voor Bio-ethiek en Gezondheidsrecht, Utrecht

Waelbers KA, Stafleu F, Brom FWA (2004) Not all animals are equal differences in moral foundations for the Dutch veterinary policy on livestock and animals in nature reservations. J Agric Environ Ethics 17(6):497-515

Wenz PS (1988) Environmental justice. State University of New York Press, Albany

Wilson RP, McMahon CR (2006) Measuring devices on wild animals: what constitutes acceptable practice? Front Ecol Environ 4(3):147-154

WWF (2010) Living planet report 2010. WWF International, Gland 